\title{
CIRANDA DE SABERES: O DIÁLOGO ENTRE SABERES TRADICIONAIS E ESPECIALIZADOS, NO ÂMBITO DA PRODUÇÃO ARTESANAL
}

Márcio James Soares Guimarães

Universidade Federal do Maranhão

falecommg@gmail.com

Raquel Gomes Noronha

Universidade Federal do Maranhão

raquelnoronha79@gmail.com

Mariana Gomes Lúcio de Araújo

Universidade Federal do Maranhão

marianalucio.dois@hotmail.com
Marina Bezerra Doudement

Universidade Federal do Maranhão

marinabdoudement@gmail.com

Alice Campos Silva

Universidade Federal do Maranhão

alicecamposs@outlook.com

Frank Willian da Costa Souza

Universidade Federal do Maranhão

frank.willian.souza@gmail.com

Leandro Coqueiro Batalha

Universidade Federal do Maranhão

leo.coqueiro@hotmail.com

Resumo: Neste artigo, visamos a contribuir para uma reflexão sobre o intercâmbio de saberes e a transmissão de tecnologias sociais. Apresentaremos referências e posicionamentos sobre a questão do encontro entre designers e artesãs, os discursos e práticas nativas sobre algumas etapas de suas cadeias produtivas, especialmente àquelas ligadas aos saberes tradicionais das artesãs; os materiais, a atividade projetual e o ambiente no qual estão inseridas, de acordo com as propostas teórico-metodológicas de codesign próprias do Design Anthropology.

Palavras-chave: Tecnologias sociais; saberes tradicionais; Design Anthropology; codesign.

\begin{abstract}
In this paper, we aim to contribute to a reflection on the exchange of knowledge and the transfer of social technologies. Present references and positions on the issue of meeting between designers and artisans, speeches and native practices on some stages of their supply chains, especially those related to traditional knowledge of the artisans; materials, design activity and the environment in which they operate, according to the theoretical and methodological proposals in codesign own Design Anthropology.
\end{abstract}

Keywords: Social technologies; traditional knowledge; Anthropology design; codesign. 


\section{INTRODUÇÃO}

A determinação das formas de saber e fazer refletem o exercício do poder nas sociedades contemporâneas. No caso específico dos saberes tradicionais, estes vêm sendo paulatinamente sobrepujados pelas demandas de mercado, que impõem ritmos, quantidades, formas de entrega que não respeitam as práticas locais. $O$ estudo de uma produção tradicional local e sua comercialização em um âmbito mais amplo, e poderíamos dizer até mesmo global, requer um esforço de pesquisa que respeite a temporalidade local e que esteja em sintonia com as contingências que uma produção artesanal local enfrenta para sustentar-se cultural, ambiental e economicamente.

Neste artigo, apresentamos resultados parciais de pesquisa em duas comunidades produtoras de cerâmica, ambas situadas no Estado do Maranhão, com dinâmicas e processos produtivos bastante diferenciados. As pesquisas incidiram sobre a região denominada Baixada Maranhense e seus objetivos são mapear as práticas e tradições culturais locais, prototipá-las, promovendo ajustes negociados com os grupos, e intercambiá-las, na forma de tecnologias sociais. A prática etnográfica é tradicionalmente uma contribuição da antropologia ao campo do design. Nesta proposta metodológica que estamos vivenciando, busca-se uma via oposta: um desenvolvimento projetual da antropologia, uma forma engajada de produzir resultados socioculturais com os sujeitos da pesquisa. No design, denominamos tais práticas por codesign. Um novo campo de reflexões, o Design Anthropology (DA), surge para dar conta desse processo de abertura da prática antropológica para além dos outcomes teóricos. Uma antropologia engajada alia-se a uma atividade projetual que envolve a todos os implicados no processo.

Nos itens deste artigo apresentaremos reflexões sobre as propostas teóricometodológicas do DA que nos ajudam a pensar nosso objeto de estudo, a produção artesanal, o intercâmbio de saberes e a transmissão de tecnologias sociais; inicialmente trataremos da proposta de intercambiar conhecimentos e prototipá-los, produzindo o que vem sendo denominado por tecnologias sociais. O segundo passo é apresentar nossas referências e posicionamentos sobre a questão do encontro entre designers e artesãs, baseando-nos em discussões sobre saberes tradicionais e especializados, referenciando-nos em autores do design e da antropologia e finalmente, trazemos os debates das artesãs sobre as semelhanças e diferenças e de seus processos produtivos, assim como suas reflexões sobre o seus fazeres e saberes.

Aqui, analisaremos discursos e práticas nativas sobre algumas etapas de suas cadeias produtivas, especialmente àquelas ligadas aos saberes tradicionais das artesãs; os materiais, atividade projetual e o ambiente no qual estão inseridas são os temas que daremos relevo neste momento. Os dados apresentados foram obtidos por meio da pesquisa de campo etnográfica, empreendida nas localidades de Itamatatiua e Porto do Nascimento, nos quais se localizam os grupos produtivos; o primeiro, com o qual já temos relação de pesquisa há sete anos, enfrenta a realidade da chegada do turismo e busca o diálogo com os novos atores para incrementar a sua produção secular; o segundo grupo, as Anas das Louças, como são conhecidas, é formado por cinco mulheres da mesma família, todas chamadas Anas, que possuem reconhecimento nacional e praticam valores de mercado muito maiores que os de Itamatatiua. 


\section{ENTENDER O LOCAL PARA A EMANCIPAÇÃO SOCIAL}

De acordo com Fernandes e Maciel (2010), trabalhar com o conceito de tecnologia social pressupõe trabalhar também com transformação social, a participação direta da população, o sentido de inclusão social, a melhoria das condições de vida, o atendimento de necessidades sociais, a sustentabilidade socioambiental e econômica, a inovação, a capacidade de atender necessidades sociais específicas, a organização e sistematização da tecnologia, o diálogo entre diferentes saberes (acadêmicos e populares), a acessibilidade e a apropriação das tecnologias, a difusão e ação educativa, a construção da cidadania e de processos democráticos, a busca de soluções coletivas, entre outros, que são sustentados por valores de justiça social, democracia e direitos humanos (FERNANDES e MACIEL, 2010, p.9).

Nos últimos sete anos, tivemos oportunidade de acompanhar o processo da chegada do turismo em comunidades artesãs do lugar e consequentemente a discussão sobre o processo de tangibilização da identidade étnica - tais territórios são terras de preto, nas representações locais, territórios quilombolas, perante a lei - e no papel do designer neste contexto (NORONHA, 2015a, 2015b). Durante nossa estada em campo fomos solicitados a resolver questões de toda natureza, deste ajuste nas formas dos produtos às questões organizacionais e simbólicas, como a divisão financeira dos lucros obtidos com as vendas.

Manzini (2015) nos indica que, cada vez mais, os denominados designers experts, os profissionais e detentores do saber especializado, exercem uma função de mediadores de questões que envolvem a gestão da produção, e no desenvolvimento de ferramentas que possibilitem tais mediações. A dimensão da materialidade surge como categoria fundamental para entender nosso papel nos dilemas culturais contemporâneos, parafraseando o antropólogo James Clifford (1988).

Entre os diversos dilemas identificados, percebemos diversos entraves nas cadeias produtivas de valor; questões de comercialização, de acabamento nos produtos; transporte e embalagem, e os de natureza simbólica, como a estética das peças produzidas, a representação da história do lugar nos souvenires, entre outros. De todos estes, dedicamos especial atenção para as estratégias vernaculares soluções projetuais nativas - e porque não dizer - tecnologias sociais - que as artesãs desenvolvem em relação às matérias primas empregadas em sua produção e a relação com a sazonalidade do lugar.

Para que as cadeias produtivas realmente produzam valor, são necessários o entendimento e a reflexão sobre tais aspectos vernaculares da produção artesanal que a alçam a um patamar específico nesse processo de geração de valor, por meio da valorização da identidade cultural local.

Essa demanda em lidar com aspectos socioculturais e políticos vem sendo uma das atribuições do designer na contemporaneidade. A complexidade do mundo em que vivemos requer do designer um posicionamento mais engajado (CARDOSO, 2012; MANZINI, 2015), assim como vem-se percebendo, nas próprias ciências sociais, um esforço para sair da teoria, consolidada em laudos e artigos acadêmicos, para a aplicabilidade de seus resultados.

Ao lançarmos um olhar atento sobre as práticas produtivas, sobre as soluções para os problemas cotidianos de suas próprias produções, estamos colaborando como designers experts - no processo de tangibilização e materialização dos problemas sociais enfrentados por tais comunidades. 
A criatividade aplicada à tais processos promovem a atividade projetual entre leigos. Manzini (2015) caracteriza tal atividade como uma contingência contemporânea e como uma forma de exercer a própria cidadania. O que por ele é denominado por design difuso, o antropólogo Tim Ingold (2012) caracteriza como uma habilidade inerente a qualquer ser humano e esta capacidade se estabelece no contato entre os seres humanos e a natureza.

O recém instituído campo do Design Anthropology lida com estas questões complexas que reposicionam tanto o designer, quanto o antropólogo e os stakeholders envolvidos nestes processos colaborativos (HALSE, 2010; BRANDT, 2008). A metodologia que empregamos nesta pesquisa, cujos resultados preliminares apresentamos, visa a essa complexificação do contato dos implicados no processo por meio do que vimos chamando Ciranda de Saberes: um intercâmbio entre grupos produtivos de determinada região, mediado por designers. Nossa tarefa não é atuar projetualmente, mas facilitar processos de troca de saberes entre os grupos, criando ferramentas e protótipos que colaborem para a tomada de consciência e empoderamento de tais grupos. A dimensão material- os artefatos em geral, incluindo-se as imagens - traz à tona memórias, elementos perdidos e ocultos no imaginário, como nos afirmam Clifford (1987) e Pink (2001). A tangibilização da teoria, como proposto pelas metodologias do DA, permite o deslocamento do próprio lugar de fala e do próprio ponto de vista, propiciando a possibilidade de visualizar novas possibilidades e imaginar futuros.

\section{ANAS, ELOÍSAS, NEIDES E CANUTAS... ENCONTRO DE GRUPOS PRODUTIVOS}

O artesanato desenvolvido pelas Anas das Louças e pelas Mulheres de Itamatatiua é fruto do acúmulo de saberes transmitidos por gerações, um longo período onde outras Anas, Eloísas, Neides e Canutas herdaram e detiveram o conhecimento tácito de inúmeras técnicas de extração e manipulação do barro, que continua sendo transformado em artefatos que exprimem seus valores e sua visão de mundo.

Quando oportunizamos o encontro destas mulheres, permitimos que esta história se ramifique. Ingold (2012) argumenta que vivemos em um mundo de materiais, e que as coisas - e não os objetos - existem em fluxos, dando primazia às reflexões que enfatizem os materiais e as forças em detrimento do modelo hilemórfico, baseado na dicotomia matéria versus forma. Nesse sentido, Ingold afirma que o conhecimento objetivo e dicotômico difere de um outro tipo de conhecimento, que é aquele que advém de uma experiência de vida e do trabalho com o material. Nas palavras do autor "é um conhecimento nascido de uma percepção sensorial e um engajamento prático; não entre a mente e o mundo material, mas da habilidade do praticante participando do mundo dos materiais." (INGOLD, 2011, p.31, tradução minha). É este conhecimento prático - pela habilidade do modelar - que venho denominando nesta pesquisa por saber-fazer.

O saber-fazer, termo composto por duas atividades distintas e complementares, alia o conhecimento apreendido de geração para geração e a prática, a habilidade manual, adquirida corporal, no contato também geracional.

A discussão que propomos avança pelo entendimento de que a categoria saber-fazer difere de produção artesanal. Pensá-la a partir de um conhecimento corporal do material sobre o qual - e com o qual se projeta uma peça - é reconhecer 
um nível de equiparação hierárquica entre seres humanos e natureza. O modelo hilemórfico criticado por Ingold (2012) é o oposto desta abordagem.

\section{1 - Processo Produtivo}

O processo produtivo das Anas, em Porto do Nascimento - Município de Mirinzal - MA, tem seu princípio na extração do barro, que se apresenta em duas camadas distintas: o barro preto - utilizado para produção de rejunte em construções civis; e uma segunda camada mais profunda utilizada para a produção de peças utilitárias do artesanato por conter uma quantidade inferior de impurezas. Este procedimento ocorre nas regiões de campo e é realizado durante o período de estiagem, que ocorre de agosto a dezembro.

Após a extração, como relatado por Ana Domingas, o barro fica armazenado no período equivalente a um ano, "adquirindo uma aparência petrificada". Após este período limpa-se o barro, utilizando um processo manual onde são adicionadas cinzas do taquipé ${ }^{1}$, que garante maciez à pasta cerâmica e resistência durante a queima.

A partir desta massa, são produzidas serpentinas com o barro curtido (maturado) e limpo (neste estágio já não existem bolhas de ar, nem impurezas), moldadas em espessuras e comprimentos diversos que unidas por modelagem manual da peça, dão origem às peças utilitárias. No processo de acabamento, utiliza-se para polir o najá, um fruto de uma espécie de palmeira da região, que confere ao artefato brilho e uniformidade. Posteriormente, as louças são levadas para um celeiro para a secagem e, depois de alguns dias, serem submetidas aos processos de "esquente ${ }^{2 "}$ e queima.

A queima é realizada ao ar livre, as louças são dispostas em círculo uma ao lado da outra de cabeça para baixo, posicionadas de modo que não deformem, em seguida são cobertas por "caçambas" ${ }^{3 "}$ de pau de najá ${ }^{4}$ ou de juçareira, que, conforme relato das artesãs, garantem uma cor diferenciada às peças.

As louças ainda aquecidas são retiradas e impermeabilizadas com a resina do jutaizeiro, a jutaicica5; que é aplicada à parte interna das peças, sobretudo nas que serão utilizadas para o consumo de líquidos.

Em Itamatatiua o processo inicia-se na extração do barro, que é realizada ao cavarem buracos no campo. Acontecendo entre os meses de outubro e dezembro, pois o campo está seco; podendo ser realizada em agosto e setembro, caso haja

\footnotetext{
${ }^{1}$ Taquipé é um arbusto de médio porte, encontrado próximo a região onde se desenvolve o processo de produção. Dele se retira a casca, que é queimada até que se tornem cinzas para serem utilizadas no processo inicial de preparação do barro.

${ }^{2}$ Cascas e cachopas (a parte fibrosa) de coco babaçu são postas no centro de um círculo formado pelas louças, de modo que a fogueira a ser acesa esquente-as e lhes retire o restante de umidade existente.

${ }^{3}$ Cascas de árvores, pecíolos e bainhas das folhas das palmeiras.

${ }^{4}$ Najá (Maximiliana maripa) é uma espécie de palmeira de porte mediano, rica em fósforo, magnésio e ácidos graxos cujas cascas, são coletadas durante o verão, por se apresentarem mais leves e secas, são empregadas no processo de queima e permitem uma maior combustão no processo.

${ }^{5}$ Das "feridas" do Jatobá, origina-se uma resina que é utilizada na impermeabilização das peças: a jutaicica. A aplicação desta resina é realizada no processo de queima, onde após ser cristalizada é presa ao chupeto (utensilio de madeira semelhante a uma colher) e espalhada no interior de peças abertas que não serão utilizadas para preparar alimentos.
} 
encomendas e a falta de matéria prima. Sendo transportado em $\operatorname{cofos}^{6}$, com auxílio de animais ou de carros.

Ao chegar à sede da associação, o barro é molhado por meio de uma mangueira, permanecendo em um tanque até ser modelado. Antes de ser colocado na maromba (maquinário que auxilia no processo de extrusão da argila, tornando a pasta cerâmica homogênea e compactada), é necessário misturá-lo com areia; são feitos bolos alongados, com esta mistura.

Ao ser levado para a maromba, duas artesãs trabalham neste processo, os bolos de barro amassados são colocados dentro do orifício por uma artesã e amassados com pilão de madeira por outra. Após ter seu processo de preparação na maromba, o barro precisa ser molhado e amassado com areia para então ser modelado.

A modelagem do barro depende do tamanho das peças, quando a peça é pequena as artesãs realizam o processo em pé, com o barro em cima de uma bancada e quando a peça é grande são modeladas no chão. Os potes ou alguidares pequenos são modelados em cima da bancadacom uma pequena camada de areia que serve como apoio para a base e que segundo as artesãs serve para fazer o pote rodar.

A base é feita com uma bola de barro e amassada manualmente até que se torne um círculo de dois centímetros de espessura, em seguida são adicionadas as serpentinas (longas tiras de barro enroladas) em espiral e sobrepostas até que atinjam formato vertical para em seguida serem modelados pelas artesãs manualmente dando boca ao pote, que pode ser aberta ou fechada.

Os potes grandes são modelados no chão, onde a artesã senta-se com as pernas abertas e entre elas coloca a base e modela as serpentinas manualmente. As peças não simétricas, animais e bonecas são modeladas a partir de uma bola de barro.

São utilizados alguns instrumentos tais como colheres, facas, estiletes e cuipéuas (espátula formada por um pedaço de cabaça), para nivelar a superfície das peças (interna e externamente). Nessa etapa de acabamento são adicionados detalhes as peças. Para adicionar outras partes as peças, utiliza-se a barbotina, uma espécie de pasta de barro fluida, feita de restos de barro raspado e peneirado, que tem sua estrutura final em uma cola de textura fina. Ao final desta etapa, a peça é levada para secar ao vento.

Após estar seca a peça passa pelo processo de raspagem, que tem como objetivo deixar a superfície da peça uniforme, utiliza-se a faquinha, desbastadores e cuipéua. Por fim, é passada uma esponja. Depois de raspada ela retorna a secagem, as artesãs guardam as peças em caixas d'água com objetivo de retardar a secagem; permanecem neste estado até que se tenha a quantidade necessária para colocar no forno.

Antes de serem levadas para a queima há o acabamento final, onde todas as peças são lixadas com uma lixa fina e depois com um seixo, uma pedra de rio. Por fim é passado um escovão para dar brilho a peça. Depois de todos esses processos, a peça cerâmica é levada ao forno, nesta fase são todas as colocadas no forno, amontoando os potes, emborcados. Colocando os maiores como base e os menores por cima, até chegar ao topo do forno, que tem sua boca fechada com cacos de potes quebrados.

A queima dura um dia inteiro, depois as peças descansam por uma noite com as brasas. Na manhã seguinte, as brasas são apagadas molhando-as e as peças

\footnotetext{
${ }^{6}$ Artesanato em cestaria, típico da Região Nordeste.
} 
descansam por mais um dia e meio, para esfriar. O forno grande pode suportar até 500 peças e no menor, 300 peças. As artesãs realizam em média uma queima por vez.

Existem algumas peças que são pintadas após a queima, majoritariamente as bonecas, é utilizada tinta acrílica ou tinta para tecido, a denominada pintura a frio. Após a queima, é feita uma verificação para separar as peças que racharam durante o processo de queima, as que sofreram algum tipo de danificação são descartadas.

Para avançarmos na discussão, dedicamo-nos a observar como se dá a percepção das artesãs sobre o seu próprio processo produtivo e como se constrói o diálogo entre os dois grupos produtivos, considerando-se suas estratégias vernaculares de reprodução cultural, ambiental e econômica.

\section{REFLEXÕES SOBRE A TROCA DE SABERES}

Em Ao promover o encontro destes dois grupos produtores de cerâmica, há um intercâmbio de informações sobre os modos de produção, através deste observa-se que há uma troca e enriquecimento dos saberes já perpetuados. Demonstrados nas observações que podem ser realizadas após serem feitas comparações dentre elas.

Enquanto a comunidade de artesãs de Itamatatiua, é composta por mulheres sem laços de parentesco que trabalham juntas em uma associação; em Porto do Nascimento, é composta por mulheres de uma mesma família, onde os laços afetivos são mais intensos, mas a produção é realizada individualmente, em suas próprias casas.

A produção nos dois locais é diversa, enquanto as Anas têm sua produção voltada para utilitários, que em sua maioria são louças e que podem ir ao fogo. Em Itamatatiua há predominância da produção de peças decorativas e uma parcela menor de utilitários, que devido ao seu modo de produção, não é comumente utilizada para o cozimento de alimentos.

Há a utilização do najá pelas Anas das louças, para polir as peças. Já em Itamatatiua, segundo Eloísa, utiliza-se pedra seixo, de beira de rio e depois escova de lavar. Na etapa da queima, das Anas pode-se queimar pequenas quantidades de peças, enquanto em Itamatatiua é necessário que se tenha um acumulo de peças para que exista o preenchimento total do forno.

Ao fazer essas observações, pode-se concluir que ao promover o encontro destas artesãs há não só o enriquecimento dos saberes tradicionais, mas o aprendizado de novas técnicas a serem aplicadas em sua produção, sendo esse durante o processo produtivo e também no modo de comercialização.

\subsection{Queima, coloração, resistência ao fogo e o taquipé}

O encontro das artesãs possibilitou aos pesquisadores e às duas comunidades, a descoberta de modos de fazer e insumos que distinguem suas produções. Os diálogos estabelecidos, demonstram a influência do processo de queima e a importância da adição de insumos vegetais na confecção das louças, conforme citado pelas Anas:

Ana das Graças: Ei, a senhora queima no forno hein?

Ana Domingas: É no forno, não é como a gente.

Eloísa: É no forno. Mas a gente tem vontade de aprender a queimar assim, né? Porque as vezes a gente quer ter uma encomenda rapidinho. 
Pesquisadora: E no forno tem que encher o forno todo, só uma vez por mês pra produzir essa remessa. É um forno enorme.

Ana Domingas: Aqui não, pode queimar até três peças, quatro peças. A gente bota tudo assim em cima do tijolo e bota arrodeado no ar livre. Agora só que esse barro de vocês não vai aguentar. Não aguenta porque não tem o taquipé.

As cinzas do taquipé, obtidas com a queima da casca deste arbusto, proporcionam às peças resistência, plasticidade e consequentemente a sua não fragmentação no processo de queima. A conversa travada na varanda de Ana Domingas, durante um encontro entre as artesãs, em nossa presença, trouxe diversas questões como a queima, a quantidade de peças produzidas em cada queima, a demanda de produção e a resiliência do barro ao fogo, considerando as duas diferentes formas de queima das duas cadeias produtivas.

As Anas das Louças queimam suas peças "no tempo" e as louceiras de Itamatatiua utilizam o forno. O combustível é o mesmo, a lenha. O primeiro processo consiste em cavar um buraco raso, colocar a louça (no máximo uma dezena de peças médias) e depois cobrir com folhas e lenha e atear fogo. $\mathrm{O}$ calor recebido pelas peças é intenso e direto, e isso provoca manchas deixadas pelas labaredas e, dependendo de cada tipo de vegetal utilizado na fogueira, produz tonalidades diferentes. Este recurso é utilizado de forma consciente pelas Anas, o que garante um diferencial estético na coloração de suas peças. Ainda que não haja controle sobre o resultado - há uma antecipação desse resultado - caracterizando o processo identificado por Ingold como foresight - a antevisão do artesão que caracteriza uma intenção, e que na visão do autor, caracteriza uma atividade projetual.

No caso de Itamatatiua, a queima é feita em grande escala. O maior forno comporta até 20 potes grandes. Realizar uma queima com o forno vazio é um desperdício em termos ambientais e econômicos, porque gasta-se muita lenha e também há um preço fixo, em torno de $\mathrm{R} \$ 80,00$ que se paga ao queimador, homem que executa e acompanha o processo de queima por quase 48 horas.

A temperatura do forno é controlada de modo empírico, com a adição de lenha seca e lenha verde, que aumentam e diminuem a intensidade do fogo, respectivamente.

\subsection{Moldando louças e a si mesmas}

O refinamento e aprendizado da técnica junto ao interesse pelo aprimoramento da qualidade dos artefatos, levou a produção artesanal a proporcionar uma renda antes inexistente para a maioria das mulheres envolvidas. Para além do ganho monetário, identifica-se hoje que as artesãs vivenciam experiências de tomadas de decisões e controle, antes não exercidas, conforme os depoimentos de Ana Domingas, Nazaré e Canuta:

Canuta, de Itamatautia: "A cerâmica de lá é muito boa, Itamatatiua é o manual e Rosário é a forma. A gente tem que vender, por que é desse que a gente tira o sustento, que a gente tirou pra criar os nossos filhos, se não vender, fica difícil comprar qualquer coisa. Nossa mãe que ensinou, nossa avó, é uma herança e nunca tem que terminar, é uma herança muito boa e todo mundo gosta das peças da gente." 
Nazaré, de Itamatautia: "Aprendi a cerâmica com minha mãe, quando eu tava com 11 anos a minha mãe era viva. Quando eu tava com 12 minha mãe já morreu, ai eu já sabia fazer várias coisas, já sabia fazer o pote, o jarro. Quando eu tinha 18 anos meu pai faleceu, mas como eu já era dona da minha venta, já me responsabilizava por minhas despesas. Ai depois arranjei filhos e maridos, comecei a fazer louça, vendia, adquiria o dinheiro e comprava as coisas pro meu filho. Por isso tenho o maior orgulho e nunca largo de fazer, por que foi uma coisa muito importante pra mim, criei meus filhos foi fazendo louça. Por isso que gosto e nunca deixo de fazer, só depois que morrer. É uma coisa muito importante. "

Ana Domingas, de Porto do Nascimento: "Enquanto eu puder, não vou deixar de trabalhar. É uma profissão muito boa, esse barro na mão da gente"

Ana Domingas, de Porto do Nascimento: "Quer dizer que ele acha uma bobagem, bobagem nada. De maneira nenhuma, e eu gosto é da minha profissão"

A ocupação com a atividade artesanal constitui uma fonte de renda muitas vezes superior à obtida por seus companheiros e lhes permite acesso a serviços outrora não usufruídos. Com os ganhos obtidos pela comercialização das peças, muitas destas artesãs passaram a prover, de modo regular, o acesso aos bens de consumo, educação e lazer em seus ambientes familiares. No depoimento de Ana Domingas é possível observar que o trabalho viabilizou notoriedade, modificando suas relações no âmbito familiar e de trabalho:

Ana Domingas, de Porto do Nascimento: "Eu não estudei numa faculdade
pública. A minha foi quase titular, mas isso aqui me ajudou muito. Eu pagava
a minha faculdade, eu pagava a minha, pagava a da minha filha. Me ajudou
muito. Quando chegava no verão que eu tava fazendo essas coisas ai, eu
ficava despreocupadinha, quando chegava no final do mês, a minha
mensalidade da minha faculdade, da minha e da minha filha, tava
prontinha"

A consciência do próprio valor e a satisfação pela ocupação são citados como os maiores benefícios adquiridos e se ajustam aos parâmetros de identificação do empoderamento feminino apresentados por Stromquist (2002): como a construção de uma autoimagem e confiança positiva; o desenvolvimento da habilidade para pensar criticamente; a construção da coesão de grupo; e a capacidade de agir.

Percebemos nos diálogos estabelecidos, que o artesanato, considerado atividade primordialmente feminina no Estado do Maranhão, também auxilia na desconstrução de posicionamentos sociais preestabelecidos por meio de atitudes proativas, de acordo com a capacidade de agir defendida por Stromquist, a ação percebida em cinco níveis de mudanças: bem-estar; acesso aos recursos; conscientização; participação; controle; maior igualdade; e maior empoderamento.

\section{CONSIDERAÇÕES FINAIS}

Pensar no próprio termo "tecnologias sociais" já é bastante para provocar inquietação: o saber, o conhecimento produzido a partir de um ofício, que é a base etimológica da palavra tecnologia já inclui - a priori - a concepção do "social"! 
Conceber um projeto que valorize e se debruce sobre esta questão é uma forma de valorização dos saberes e fazeres tradicionais e sua capacidade de diálogo com as questões e complexidades da contemporaneidade. Ao pesquisar e projetar com as artesãs de Itamatatiua, por exemplo, encontramos diversos entraves à execução de um projeto financiado por um edital de extensão do governo federal que não contemplava o pagamento de diárias ou remuneração por oficinas e palestras para quem não possuísse títulos acadêmicos.

A possibilidade de trazermos o saber local associado às metodologias acadêmicas como chaves para a solução ou amenização das dificuldades das comunidades pesquisadas é um grande passo para chegarmos a estratégias que sintonizadas com os próprios lugares/povoados onde incidirá a pesquisa. A possibilidade de êxito das soluções projetuais cresce exponencialmente já que o empoderamento da comunidade e autoestima são elementos fundamentais para consolidar este tipo de ação.

Desta forma, esta investigação estimula e colabora com a superação de um modelo e um padrão tradicionais de pesquisa e de ciência. É um espaço fértil para a observação e os processos de co-projetação entre designers e os detentores dos saberes tradicionais.

\section{REFERÊNCIAS}

BRANDT, Eva et al. Formating Design Dialogues - Games and Participation. In: BINDER, T; BRANDT, E; GREGORY, J. (guest editors). CoDesign - International Journal of CoCreation in Design and the Arts, Volume 4, Number 1, pp. 51-64. Taylor \& Francis. March, 2008.

CARDOSO, Rafael. Design para um mundo complexo. São Paulo: Cosac Naify, 2012. CLIFFORD, James. The Predicament of Culture. Cambridge: Harvard University Press, 1988.

FERNANDES, Rosa Maria Castilhos; MACIEL, Ana Lúcia Suárez. Tecnologias Sociais: experiências e contribuições para o desenvolvimento social e sustentável. Fundação Irmão Otão: Porto Alegre, 2010.

HALSE, Joachin; BRANDT, Eva; CLARK, Brendon; BINDER, Thomas. Rehearsing the future. The Danish Design School Press: Copenhagen, 2010.

MANZINI, Ezio. Design, when everybody designs. An introduction to Design for Social Innovation. The MIT Press: Cambridge/London, 2015.

INGOLD, Tim. Trazendo as coisas de volta à vida: emaranhados criativos num mundo de materiais. In: Horizontes Antropológicos, Porto Alegre: ano 18, n.37, p. 25-44, jan./jun. 2012.

Preface. In: Being Alive. Essays on movement, knowledge and description.New York: Routledge, 2011.

NORONHA, Raquel. Dos quintais às prateleiras: as imagens quilombolas e a produção da louça em Itamatatiua - Alcântara - Maranhão. 289f. Tese (Doutorado em Ciências Sociais) - Instituto de Filosofia e Ciências Humanas - Programa de Pós-Graduação em Ciências Sociais. Universidade do Estado do Rio de Janeiro, Rio de Janeiro, 2015a. 
Era uma vez no quilombo: narrativas sobre turismo, autenticidade e tradição entre artesãs de Alcântara (MA). Textos escolhidos de cultura e arte populares, Rio de Janeiro, v.12, n.1, p. 43-60, mai. 2015b.

PINK, Sarah. Doing visual ethnography. Images, media and representation in research. London: Sage, 2001.

STROMQUIST, Nelly P. "Education as a means for empowering women". In J. Par-part, S. Rai \& K. Staudt (eds), Rethinking empowerment: gender and development in a global/local world. London: Routledge, 2002. 